\title{
Handgrip strength and its association with noncommunicable diseases and their risk factors among elderly individuals in Malaysia
}

\section{Shamsul Azhar Shah ( $\sim$ drsham@ppukm.ukm.edu.my)}

Department of Community Health, Faculty of Medicine, Universiti Kebangsaan Malaysia, Kuala Lumpur

Nazarudin Safian

Department of Community Health, Faculty of Medicine, Universiti Kebangsaan Malaysia, Kuala Lumpur

Saharuddin Ahmad

Department of Family Medicine, Faculty of Medicine, Universiti Kebangsaan Malaysia, Kuala Lumpur

Mohd Rohaizat Hassan

Department of Community Health, Faculty of Medicine, Universiti Kebangsaan Malaysia, Kuala Lumpur

Zulkefley Mohammad

Department of Community Health, Faculty of Medicine, Universiti Kebangsaan Malaysia, Kuala Lumpur

Siti Rohani Nurumal

Department of Community Health, Faculty of Medicine, Universiti Kebangsaan Malaysia, Kuala Lumpur

Wan Abdul Hannan Wan Ibadullah

Department of Community Health, Faculty of Medicine, Universiti Kebangsaan Malaysia, Kuala Lumpur

Juliana Mansor

Department of Community Health, Faculty of Medicine, Universiti Kebangsaan Malaysia, Kuala Lumpur

Yugo Shobugawa

Department of Active Ageing (donated by Tokamachi city, Niigata Japan), Niigata University Graduate School of Medical and Dental Sciences, Niigata

\section{Research Article}

Keywords: handgrip strength, noncommunicable disease, risk factor, JAGES

Posted Date: November 30th, 2020

DOI: https://doi.org/10.21203/rs.3.rs-111875/v1

License: @ (1) This work is licensed under a Creative Commons Attribution 4.0 International License. Read Full License 


\section{Abstract}

Background: Handgrip strength (HGS) is indicative of overall physical health among older people. A reduction in HGS may be associated with an increased risk of disease. This study aims to assess the association between HGS and noncommunicable diseases (NCDs) and the related risk factors.

Methods: One thousand two hundred four (1204) participants from four areas in Selangor state, Malaysia, were recruited. A comprehensive face-to-face interview based on the Bahasa Malaysia version of the Japan Gerontological Evaluation Study (JAGES-BM) questionnaire was administered, followed by HGS assessments by a handgrip dynamometer.

Results: The mean age of the participants was 68.7 (SD 6.36) years. A total of 691 participants (57.4\%) were male, and 513 (42.6\%) were female. The mean HGS was 30.0 (SD 7.53) kg for men and 19.4 (SD 5.28) kg for women. Analysis of covariance (ANCOVA) showed that factors associated with HGS among elderly males were age group, employment status, smoking status, alcohol consumption, moderate physical activity, BMI class, diabetes mellitus and selfrated health status. For females, the significant factors were age group, moderate and light physical activity, and BMI class.

Conclusions: The study contributed to a better understanding of factors associated with HGS among elderly individuals in Malaysia. Consequently, HGS may be recommended as an assessment for identifying elderly individuals at risk of NCDs and poor health status.

\section{Trial Registration}

Not applicable

\section{Background}

Noncommunicable disease (NCDs) are responsible for $70 \%$ of all deaths worldwide and comprise diseases such as heart disease, stroke, cancer, diabetes and chronic lung disease [1]. Thus, this is one of the major public health challenges, as NCDs are becoming increasingly common among elderly individuals. It was stated in a report that 22 million of 36 million annual death among individuals older than 70 years are attributed to NCDs [2]. On the other hand, health expenditure among elderly individuals, including direct and indirect costs, is also increasing overall in Malaysia [3]. Therefore, it is necessary to determine elderly health status using recommended tools to commence control and prevention earlier among individuals in this population.

One of the essential determinants of healthy ageing is muscle strength [4]. A reduction in muscle strength has been shown to impair normal bodily function. The ageing process, physical inactivity and malnutrition lead to muscle deterioration among older people. In contrast, if elderly individuals were to be empowered with knowledge and education regarding a healthy diet and regular physical activity, reduced muscle strength could potentially be counteracted and improved despite the physiological ageing process [5]. It has been scientifically proven that improved physical activity and resistance exercise enhance the muscle strength and function of elderly people, even if they are burdened with severe disability [6].

To date, one of the easiest and most readily available measures of muscle strength is a handgrip strength test. Extensive scientific studies have proven that there is a significant association between handgrip strength and the strength of other muscles in the assessment of both healthy individuals and elderly people with some pathology. This practical measurement of handgrip strength is therefore widely used as a single indicator of overall muscle strength, especially in the elderly population $[7,8]$.

Handgrip dynamometers are widely used to measure maximum isometric handgrip strength with excellent intertester and test-retest reliability [9]. Low handgrip strength is commonly indicative of weak upper extremity strength and lower extremity function [10]. In the elderly population, this is usually observed as reduced mobility and increased dependency in their activities of daily living and is predictive of body function and mortality. Indeed, handgrip strength is considered one of the reliable measures of physical decline and future outcomes among the elderly population according to the World Health Organization [11].

No studies to date have been conducted on handgrip strength as a general health measurement among the elderly population in Malaysia. Indirectly, this may result from a lack of usage of handgrip measurements in clinical practice. Therefore, this study was carried out with the aim of assessing the association of handgrip strength measurement in the elderly population with noncommunicable diseases and the related risk factors. We hope that as a result of this study, HGS will be integrated into elderly assessments in the clinical setting.

\section{Methods}

\section{Study Design}

This was a cross-sectional study conducted among adults aged 60 years and above in four areas in Selangor State, Malaysia. Two rural and two urban areas were selected randomly from the list of housing areas or villages. The study was conducted from 1 December 2018 to 30 April 2020 and included 1204 respondents who were randomly selected. The interview was conducted in a quiet face-to-face environment by trained research assistants. The study used the Bahasa Malaysia version of the Japan Gerontological Evaluation Study (JAGES-BM) questionnaire, which adopted from the Japan version of JAGES [12]. It has multidimensional variables, namely, demographic, socioeconomic status, family environment, health status and medical history, and lifestyle factors, including physical activity indicators.

The inclusion criteria in this study were Malaysians aged 60 years old and above who were able to converse in the Malaysian language. All respondents were screened for the possibility of poor cognitive function using the Abbreviated Mental Test score (AMT). Those who received scores less than seven were excluded from the study. 
Handgrip strength was measured using a T.K.K. 5001 GRIP-A from Takei Scientific Instrument Co. Ltd. (Japan). Handgrip strength was measured twice in each of the respondents with the dominant hand, and the mean was taken for data analysis.

\section{Covariates}

Demographic variables included age, sex, marital status and household composition. Age was categorized into the following three categories: $60-74$ years, 75-84 years and $\geq 85$ years. Marital status was categorized into married, widowed, divorced, never married, and other. The 2019 income structure of the Department of Statistics of Malaysia was used for the household income classification. B40 is the base group or bottom $40 \%$ of individuals who earn less than RM4,850 in monthly household income, while M40 is a middle-class group or the middle 40\% of individuals who earn between RM4,851 and RM10,959. T20 is an upper-class group or the top $20 \%$ of individuals who earn more than RM10,959 [13]. Lifestyle factors that were included in the study were smoking, alcohol consumption, betel chewing and physical activity. All the questions were based on JAGES-BM, which assesses dose response. Weight and height were measured twice to calculate body mass index (BMI). The Malaysian BMI classification was used as a reference [14]; underweight was defined as BMI <18.5 $\mathrm{kg} / \mathrm{m}^{2}$, normal was $18.5-22.9 \mathrm{~kg} / \mathrm{m}^{2}$, overweight was $\geq 23 \mathrm{~kg} / \mathrm{m}^{2}$, preobese was $23.0-27.4 \mathrm{~kg} / \mathrm{m}^{2}$, obese I was $27.5-34.9 \mathrm{~kg} / \mathrm{m}^{2}$, obese II was $35.0-39.9 \mathrm{~kg} / \mathrm{m}^{2}$ and obese III was $\geq 40 \mathrm{~kg} / \mathrm{m}^{2}$. Participants were also asked whether they had hypertension, heart disease, diabetes, stroke, cancer, dyslipidaemia, depression, or difficulties remembering or concentrating and were asked about their self-rated health status. The answer was yes or no, except for on the question 'difficulties in remembering or concentrating' and 'self-rated health status', which had four-option answers. In addition, the study used the Japanese version of the 15-item Geriatric Depression Scale (GDS) to assess depressive symptoms in older adults. The GDS score ranges from 0 to 15, with higher scores indicating more severe symptoms.

\section{Data Analyses}

To determine the associations among the study variables, one-way analysis of variance (ANOVA) and independent t-tests were carried out. Post hoc Bonferroni tests were used when homogeneity of variance assumptions were met. Moreover, post hoc Tamhane's test was used if the assumed homogeneity of variance was violated. Spearman's correlation was used to assess the relationship between HGS and GDS. For multivariate analysis, analysis of covariance (ANCOVA) was used to test the main effect associated with the dependent variable. A P-value of less than 0.05 was considered to indicate significance in all tests. Analyses were performed using IBM SPSS version 21.0 (IBM Corp., Armonk, NY, USA).

\section{Permission and Ethical Considerations}

The study was conducted in accordance with the principles of the Declaration of Helsinki, whereby the participation was on a voluntary basis, and the rights and wellbeing of the participant were protected. Participant information sheets and consent forms were given to the participants after they received a thorough explanation of the study. Participants not providing consent were not interviewed. The anonymity of all the participants was guaranteed by the creation of a code based on their location. The study was approved by the Research Ethics Committee of Universiti Kebangsaan Malaysia (UKM) (approval code: FF-2018-532).

\section{Results}

\section{Sociodemographic Characteristics}

Participants were aged between 60 and 91 years with a mean age of 68.7 (6.36) years. Age was further classified into three age groups, and the overall older age group was significantly associated with lower handgrip strength (HGS) $[F(2,1202)=78.05$. $p<0.001]$. There were slightly more males $(57.4 \%)$ than females (42.6\%). There was a significant difference in mean HGS between elderly males $(30.0$ (SD 7.5) kg) and elderly females (19.4 (SD 5.28) $[\mathrm{F}(1,1202)=746.12$, $\mathrm{p}$ <0.001]. Most of the participants were married and lived with their spouse (65.6\%). Our study revealed that higher HGS among older people was significantly associated with marital status and cohabitating $[F(4,1199)=72.61 . p<0.001]$. Post hoc Tamhane's test revealed that those who were married (living together) had significantly higher HGS than those who were widowed or divorced. The majority of participants lived with blood-related family members ( $94.2 \%)$, and high HGS was significantly associated with living with blood-related family members over living alone $[F(1,1201)=10.58$, $p<0.001)$. However, the analysis within sex groups showed no significant association between HGS and household composition. In terms of educational level, $10 \%$ of participants had no education, $44.0 \%$ had a primary school education, and $17.5 \%$ had studied at the university, vocational or high school level. Those who studied at the university, vocational and high school level had a significantly higher HGS than those who had no school $[F(7,1196)=20.56, p<0.001]$. A significant proportion of participants $(72.1 \%)$ had retired from their job, $14.0 \%$ were still working and $13.9 \%$ never had a job. Those who were employed had a significantly higher HGS than those who retired $[F(2,1201)=88.72, p<0.001]$. Post hoc Tamhane's test also revealed that those who retired from a job had a significantly higher HGS than those who never had a job. Last, regarding household income, the majority of older people (86.7\%) were in the B40 group. Those in the B40 group had a significantly lower HGS than those in the M40 group, but they had significantly higher HGS than those in the 'no income' group [F(3,1200)=5.75, $p=0.003]$. However, there was no significant difference when comparing the HGS in the income group by sex. Table 1 shows the overall sociodemographic characteristics of the respondents, including the differences according to sex.

\section{Association of HGS with Lifestyle Factors}

One-way ANOVA revealed that HGS was significantly associated with smoking status and alcohol consumption among males but not among females. Table 2 below shows the association between HGS and lifestyle factors. There was a significant effect of smoking status on HGS among males at the p<0.05 level for the four levels of smoking $[F(4,686)=2.47, p=0.044]$. Men who smoked almost every day had higher HGS than those who never smoked; however, post hoc Bonferroni showed that the relationship was not significant. Moreover, regarding alcohol consumption status in the male group, the relationship was

Page $3 / 14$ 
significant with HGS $[F(3,686)=2.68, p=0.046]$. Post hoc Bonferroni showed that the mean HGS of those who were currently consuming alcohol was significantly higher than that of those who never consumed alcohol.

Overall, betel chewing status was significantly associated with $\operatorname{HGS}[F(4,1199)=2.67, p=0.003)$. Post hoc Tamhane's test showed that those who chew betel nuts almost every day had a significantly lower HGS than those who never chewed. However, analysis within sex groups showed no association of HGS with chewing betel nuts. The frequency of physical activity was also associated with HGS. Three types of physical activity (strenuous exertion, moderate exertion and light exertion) significantly affected HGS. Overall, elderly individuals who performed strenuous physical activity regularly had a significantly higher HGS than those who never or rarely exercised $[F(5,1198)=10.49, p<0.001]$. Even older people who performed frequent moderate and light physical activity had a significantly higher HGS than those who never or rarely exercised $[F(5,1198)=22.55, p<0.001$ and $F(5,1198)=6.20, p<0.001$, respectively].

\section{Association of HGS with Comorbidity}

There was a significant effect of BMI status on HGS at the $p<0.05$ level in the six BMI classes $[F(4,1199)=4.06, p=0.003]$. The post hoc Bonferroni test showed that those who were underweight had significantly lower HGS than those who were normal weight, preobese, obese I, or obese II. However, those in the preobese and obese III groups were not significantly associated with HGS.

Diabetes mellitus, cancer, self-claimed difficulties in remembering or concentrating, and self-rated health status were significantly associated with reduced HGS in males. For females, hypertension and heart disease were significantly associated with HGS. Table 3 shows the results of the statistical analysis of the relationships between comorbidities and HGS.

Although there was no association between the presence of depression and HGS, Spearman's correlation showed a significant but weak correlation between the general depression scale (GDS) and HGS (Spearman's correlation -0.172 , p-value $<0.001$ ). The R square value indicated that HGS only contributed $2.7 \%$ of the variability in the GDS. The linear regression model showed that for every 400-gram reduction in HGS, GDS increased one point. A higher GDS score indicates the presence of depression.

\section{Multivariate Analysis}

Analysis of covariance (ANCOVA) was used to test the main effect of all significant independent categorical variables associated with HGS. ANCOVA was conducted separately for males and females, and the GDS score was used as a covariate. Factors associated with HGS among male elderly individuals were age group $[F(2,639)=23.58, p<0.001]$, employment status $[F(2,639)=5.017, p=0.007]$, smoking status $[F(2,639)=2.92, p=0.021]$, alcohol consumption $[F(2,639)=2.84, p=0.037]$, moderate physical activity $[F(2,639)=6.08, p=0.001], B M I$ class $[F(2,639)=3.58, p=0.001]$, diabetes mellitus $[F(2,639)=11.94, p=0.001]$ and self-rated health status $[F(2,639)=2.99, p=0.03]$. Levene's test of equality of error variance was not significant $[F(676,14)=0.693, p=0.873)$. Thus, the variances were not significantly different, and the assumption was met. The model explained $26.7 \%$ of the variation in HGS in the study sample (adjusted $\mathrm{R}$ square $=0.267)$. Moreover, for females, the significant factors were age group $[F(2,469)=19.40, p<0.001]$, moderate and slight physical activity $[F(2,469)=2.94$, $p=0.013$ and $F(2,469)=2.67, p=0.022$, respectively] and $B M I$ class $[F(2,469)=3.61, p=0.003]$. Heart disease was almost significant $[F(1,469)=3.86, p=0.05]$. Levene's test of equality of error variance was not significant $[F(493,19)=0.802, p=0.786]$. Thus, the variances were not significantly different, and the assumption was met. The model explained $26.7 \%$ of the variation in HGS in the study sample (adjusted R square $=0.267$ ). Table 4 shows the adjusted mean HGS according to age group after controlling for potential cofounders. In both males and females, neither age group, BMI nor physical activity was associated with diabetes.

\section{Discussion}

This study revealed that the HGS level decreased significantly with age and was distinctly increased among males. A similar finding was also seen in contemporary and modern eras across the continent [15-17]. Furthermore, this finding regarding sex can be explained by the fact that females have less muscle mass than males [18] as a result of a low level of testosterone and differences in the amount of insulin-like growth factor-1 (IGF-1) and growth hormone (GH) [19]. Testosterone increases fast fibres with high glycolytic enzyme activity called type II fibres [20], which are present in high proportions in males. Moreover, high bone mineral density in males also contributed to the higher HGS among males than among females [21].

In the multivariate analysis, elderly males were found to have more factors associated with HGS than females. The proportion of elderly males who were employed and retired from a job, smoked and consumed alcohol was greater than that of females. Elderly males who were employed and retired from a job had significantly higher HGS than those who never had a job. Elderly individuals who were working or employed may participate in more active physical movement. Physical activity directly stimulates skeletal muscle and subsequently leads to improved muscle mass and higher HGS [22]. Coincidently, this study found that a lower frequency of physical activity was associated with lower HGS.

In terms of household income, although household income was not significantly associated with HGS in sex subgroups, the overall elderly sample with no income had lower HGS. This can be related to a previous study, as those in this group were physically inactive [23], which reflects that education and resources are ultimately important in preserving HGS in elderly individuals as an outcome of a healthy lifestyle.

Interestingly, this study found that alcohol consumers had higher HGS than nonconsumers. Although excessive drinking has been shown to be associated with sarcopenia [24], light-to-moderate alcohol intake has also been shown to have a protective effect against muscle mass loss [25]. Similar findings as those observed in this study were observed in a European and Koran study [26]. Further research is needed to ascertain the positive effects of alcohol consumption on HGS, in view of many other factors that can manipulate the result, such as the amount of alcohol, which was not measured in the study. Likewise, smoking was also found to be associated with higher HGS in this study. Perhaps this can be linked to other factors, such as occupation and physical activity of the smokers since most smokers comprised those with low socioeconomic status [27]. Although some studies have shown that smoking has negative effects on 
HGS [28, 29], several other studies have shown mixed results on the effect of smoking [26, 30]. Additionally, a study noted low HGS among smokers with COPD as a predictor of future acute respiratory events [31,32]. Hence, further research is needed to understand the effect of smoking on HGS.

In terms of HGS and comorbidities, this study revealed that lower HGS was significantly associated with underweight, while obesity was associated with higher HGS. This finding was consistent with a previous study [33-36]. BMI is related to fat and muscle mass; hence, low BMI is associated with low fat and muscle mass [37]. The ageing process, as well as low muscle mass, contribute to low muscle strength [38]. Additionally, poor nutritional intake, as observed in undernourished individuals, could also affect muscle mass [36, 37], but this was not measured in this study. Moreover, few studies have found contradictory results regarding the relationship between central obesity and $\operatorname{HGS}[39,40]$. Careful interpretation of the result is needed since the total weight used in the calculation of BMI, as a surrogate indicator of adiposity, includes fat mass and fat-free mass [35]. On the other hand, the presence of diabetes was associated with low HGS. Similar findings were noted in a previous study [41,42], which can be attributed to diabetic neuropathy [43, 44]. Moreover, the duration of diabetes has been shown to be associated with lower HGS $[45,46]$, which supports the theory of neuropathy since neuropathy is one of the complications of chronic poorly controlled blood sugar levels. In addition, the insulin resistance state within skeletal muscle occurs as a result of greater intramuscular adipose tissue and muscle atrophy [47], thus damaging skeletal muscle [48]. In view of the apparent association between HGS and diabetes, HGS has been proposed to be used as a diabetes screening tool among apparently healthy adults [49].

We found that better self-rated health status in elderly males was associated with higher HGS. This is in agreement with a study conducted in Indonesia [33] and could be explained by the fact that better self-rated health indicated no or less disease and that many diseases are associated with poorer self-rated health [50]. In this study, we excluded participants who had poor cognitive function. In this study, difficulty in remembering or concentrating may reflect early cognitive impairment, and we found that normal memory and concentration were associated with higher HGS. In a review performed by Fritz et al. [51], poorer cognitive function was associated with lower HGS. The reason for cognitive decline and lower HGS may be based on the understanding that motor skill learning and motor output are dependent on the activity of the frontal and parietal brain regions [52, 53]. We also found that the presence of depression was not significantly associated with HGS, and a significant but weak correlation was found between GDS and GHS. However, many studies have revealed a significant association between depression and HGS [33, 54, 55].

Given that most of the variables were self-reported and no confirmation of the data was available, the results must be interpreted carefully. However, we measured depression symptoms through the validated GDS. Nevertheless, the study is a population-based study with a large sample size. Although the respondents were chosen at random, the study sample managed to cover a good proportion of the elderly population and was similar to the demographics of the elderly population in Malaysia.

In conclusion, there are slight differences between male and female elderly individuals in the factors that influence HGS. Overall, factors such as sociodemographic factors (age, sex and household income), lifestyle factors (smoking, alcohol intake and moderate exertion of physical activity) and comorbidities (BMI and diabetes) were associated with HGS. By identifying these factors, good HGS can be preserved, which can subsequently prevent disability in elderly individuals, hence ensuring a good quality of life. Therefore, the routine use of hand grip measurement is strongly recommended in clinical practice for identifying elderly individuals at risk of poor health status.

\section{Abbreviations}

HGS: Handgrip strength; NCDs: Noncommunicable diseases; JAGES-BM: Bahasa Malaysia version of the Japan gerontological evaluation study; ANCOVA: Analysis of covariance; BMI: Body mass index; AMT: Abbreviated mental test; B40: Bottom 40\%; M40: Middle 40\%; T20: Top 20\%; GDS: Geriatric depression scale

\section{Declarations}

\section{Ethics Approval and Consent to Participate}

The Research Ethics Committee of Universiti Kebangsaan Malaysia (UKM) approved this study (FF-2018-532). Before the interview, all participants were provided with all information on the research and provided their written informed consent. Participants not providing consent were not interviewed. The anonymity of all the participants was guaranteed by the creation of a code based on their location.

\section{Consent for Publication}

Not applicable

\section{Availability of Data and Materials}

The research datasets analysed during the current study are available in the Mendeley dataset repository, [http://dx.doi.org/10.17632/hsc4k7vtfp.1].

\section{Competing Interests}

The authors declare that they have no compering interest.

\section{Funding}

The study is funded by the World Health Organization Centre for Health Development (WHO Kobe Centre - WKC). 


\section{Authors' Contributions}

SAS conceived of the study and supervised all aspects of its implementation. ZM and SRN completed the statistical analyses and led the writing of the manuscript. NS, SA, WAHWI and JM assisted with the study and data analyses. MRH and YS assisted in critical revision. All authors contributed to conceptualizing ideas, interpreting findings, and reviewing the drafts of the manuscript, and they approved the final manuscript.

\section{Acknowledgements}

We are grateful to all people from the Department of Community Health, Faculty of Medicine Universiti Kebangsaan Malaysia for their assistance in the survey. We also appreciate the head of the respective residential areas in Selangor for their cooperation and assistance.

\section{Authors' Information}

Not applicable

\section{References}

1. World Health Organization. Non-communicable diseases. 2020. http:/www.who.int/health-topics/noncommunicable-diseases\#tab=tab_1. Accessed 15 Sep 2020.

2. World Health Organization. Global action plan for the prevention and control of NCDs 2013-2020. 2015. http://www.who.int/nmh/events/ncd_action_plan/en/. Accessed 15 Sep 2020.

3. Koris R, Nor NM, Haron SA, Hamid TA, Aljunid SM, Nur AM, et al. The cost of healthcare among Malaysian community-dwelling elderly. J Ekon Malaysia. 2019;53:89-103.

4. McLeod M, Breen L, Hamilton DL, Philp A. Live strong and prosper: the importance of skeletal muscle strength for healthy ageing. Biogerontology. 2016;17:497-510.

5. Manini TM, Clark BC. Dynapenia and aging: an update. J Gerontol A Biol Sci Med Sci. 2011;67:28-40.

6. De Souto Barreto P, Morley JE, Chodzko-Zajko W, Pitkala K, Weening-Djiksterhuis E, Rodriguez-Mañas L, et al. Recommendations on physical activity and exercise for older adults living in long-term care facilities: a taskforce report. J Am Med Dir Assoc. 2016;17:381-92.

7. Takahashi J, Nishiyama T, Matsushima Y. Does grip strength on the unaffected side of patients with hemiparetic stroke reflect the strength of other ipsilateral muscles? J Phys Ther Sci. 2017;29:64-6.

8. Brogårdh C, Ekstrand E, Lexell J. Isokinetic and isometric muscle strength measurements in the upper extremity can be reliably measured in persons with chronic stroke. Physiotherapy. 2015;101:e177-8.

9. Mathiowetz V, Weber K, Volland G, Kashman N. Reliability and validity of grip and pinch strength evaluations. J Hand Surg Am. 1984;9:222-6.

10. Fragala MS, Alley DE, Shardell MD, Harris TB, McLean RR, Kiel DP, et al. Comparison of handgrip and leg extension strength in predicting slow gait speed in older adults. J Am Geriatr Soc. 2016;64:144-50.

11. World Health Organization. Integrated care for older people. Guidelines on community-level interventions to manage declines in intrinsic capacity. 2017. https://apps.who.int/iris/handle/10665/258981. Accessed 17 Sep 2020.

12. Kondo K. Progress in aging epidemiology in Japan: the JAGES project. Journal of Epidemiology. 2016:JE20160093.

13. DOSM. Pocket stats quarter 4, 2019. Department of statistics of Malaysia. 2019. https://www.dosm.gov.my/v1/uploads/files/7Publication/Infographic/PocketStats/Q4-2019/Pocket_Stats_Q4-2019.pdf. Accessed 17 Sep 2020.

14. Alamuddin N, Bakizada Z, Wadden TA. Management of obesity. J Clin Oncol. 2016;34:4295-305.

15. Alqahtani B, Alenazi A, Alshehri M, Alqahtani M, Elnaggar R. Reference values and associated factors of hand grip strength in elderly Saudi population: a cross-sectional study. BMC Geriatr. 2019;19:271.

16. Desrosiers J, Bravo G, Hébert R, Dutil E. Normative data for grip strength of elderly men and women. Am J Occup Ther. 1995;49:637-44.

17. Werle S, Goldhahn J, Drerup S, Simmen BR, Sprott H, Herren DB. Age- and gender-specific normative data of grip and pinch strength in a healthy adult Swiss population. J Hand Surg Eur Vol. 2009;34:76-84.

18. Moy FM, Darus A, Hairi NN. Predictors of handgrip strength among adults of a rural community in Malaysia. Asia Pac J Public Health. 2015;27:176-84.

19. Montalcini T, Migliaccio V, Ferro Y, Gazzaruso C, Pujia A. Androgens for postmenopausal women's health? Endocrine. 2012;42:514-20.

20. Gutmann E, Hanzlíková V, Lojda Z. Effect of androgens on histochemical fibre type. Differentiation in the temporal muscle of the guinea pig. Histochemie. 1970;24:287-91.

21. Dhananjaya J, Veena H, Mamatha B, Sudarshan C. Comparative study of body mass index, hand grip strength, and handgrip endurance in healthy individuals. Natl J Physiol Pharm Pharmacol. 2017;7:594-8.

22. Adedoyin RA, Ogundapo FA, Mbada CE, Adekanla BA, Johnson OE, Onigbinde TA, et al. Reference values for handgrip strength among healthy adults in Nigeria. Hong Kong Physiother J. 2009;27:21-9.

23. Kari JT, Pehkonen J, Hirvensalo M, Yang X, Hutri-Kähönen N, Raitakari OT, et al. Income and physical activity among adults: evidence from self-reported and pedometer-based physical activity measurements. PLoS One. 2015;10:e0135651.

24. Kwon YJ, Lim HJ, Lee YJ, Lee HS, Linton JA, Lee JW, et al. Associations between high-risk alcohol consumption and sarcopenia among postmenopausal women. Menopause. 2017;24:1022-7. 
25. Kawamoto R, Ninomiya D, Senzaki K, Kumagi T. Alcohol consumption is positively associated with handgrip strength among Japanese communitydwelling middle-aged and elderly persons. Int J Gerontol. 2018;12:294-8.

26. Kim CR, Jeon YJ, Jeong T. Risk factors associated with low handgrip strength in the older Korean population. PLoS One. $2019 ; 14: e 0214612$.

27. Lim HK, Ghazali SM, Kee CC, Lim KK, Chan YY, Teh HC, et al. Epidemiology of smoking among Malaysian adult males: prevalence and associated factors. BMC Public Health. 2013;13:8.

28. Al-Obaidi S, Al-Sayegh N, Nadar M. Smoking impact on grip strength and fatigue resistance: implications for exercise and hand therapy practice. J Phys Act Health. 2014;11:1025-31.

29. Quan S, Jeong JY, Kim DH. The relationship between smoking, socioeconomic status and grip strength among community-dwelling elderly men in Korea: Hallym aging study. Epidemiol Health. 2013;35:e2013001.

30. Lenardt MH, Carneiro NHK, Betiolli SE, Binotto MA, Ribeiro DKMN, Teixeira FFR. Factors associated with decreased hand grip strength in the elderly. Escola Anna Nery. 2016; doi:10.5935/1414-8145.20160082.

31. Martinez CH, Diaz AA, Meldrum CA, McDonald MN, Murray S, Kinney GL, et al. Handgrip strength in chronic obstructive pulmonary disease. Associations with acute exacerbations and body composition. Ann Am Thorac Soc. 2017;14:1638-45.

32. Martinez C, Diaz A, Meldrum C, McDonald M-L, Kinney G, Hokanson J, et al. Hand grip strength in smokers predicts future acute respiratory events, and is associated with body composition, independently of body mass index and measures of airflow. Chest. 2016;150(4):917A.

33. Pengpid S, Peltzer K. Hand grip strength and its sociodemographic and health correlates among older adult men and women (50 years and older) in Indonesia. Curr Gerontol Geriatr Res. 2018;2018:3265041.

34. Ramlagan S, Peltzer K, Phaswana-Mafuya N. Hand grip strength and associated factors in non-institutionalised men and women 50 years and older in South Africa. BMC Res Notes. 2014;7:8.

35. Cederholm T, Bosaeus I, Barazzoni R, Bauer J, Van Gossum A, Klek S, et al. Diagnostic criteria for malnutrition - an ESPEN consensus statement. Clin Nutr. 2015;34:335-40.

36. Mendes J, Amaral TF, Borges N, Santos A, Padrão P, Moreira P, et al. Handgrip strength values of Portuguese older adults: a population based study. BMC Geriatr. 2017;17:191.

37. Akbar F, Setiati S. Correlation between hand grip strength and nutritional status in elderly patients. J Phys Conf Ser. 2018;1073:042032.

38. Silveira TM, Sousa JB, Stringhini ML, Freitas AT, Melo PG. Nutritional assessment and hand grip strength of candidates for surgery of the gastrointestinal tract. Arq Bras Cir Dig. 2014;27:104-8.

39. De Lima TR, Silva DAS, De Castro JAC, Christofaro DGD. Handgrip strength and associated sociodemographic and lifestyle factors: a systematic review of the adult population. J Bodyw Mov Ther. 2017;21:401-13.

40. Ong HL, Abdin E, Chua BY, Zhang Y, Seow E, Vaingankar JA, et al. Hand-grip strength among older adults in Singapore: a comparison with international norms and associative factors. BMC Geriatr. 2017;17:176.

41. Neha M, Jitendra L, Lata P. Comparison of hand grip strength in diabetics and non-diabetics: an observational study. Med J Clin Trials Case Stud. 2019;3:000221.

42. Cetinus E, Buyukbese MA, Uzel M, Ekerbicer H, Karaoguz A. Hand grip strength in patients with type 2 diabetes mellitus. Diabetes Res Clin Pract. $2005 ; 70: 278-86$

43. Park SW, Goodpaster BH, Strotmeyer ES, Kuller LH, Broudeau R, Kammerer C, et al. Accelerated loss of skeletal muscle strength in older adults with type 2 diabetes: the health, aging, and body composition study. Diabetes Care. 2007;30:1507-12.

44. Park SW, Goodpaster BH, Strotmeyer ES, De Rekeneire N, Harris TB, Schwartz AV, et al. Decreased muscle strength and quality in older adults with type 2 diabetes: the health, aging, and body composition study. Diabetes. 2006;55:1813-8.

45. Sharma AK, Mukkamala N, Parmar L. To establish normative data for hand grip strength amongst elderly. Natl J Integr Res Med. 2018;9:23-7.

46. Sayer AA, Dennison EM, Syddall HE, Gilbody HJ, Phillips DI, Cooper C. Type 2 diabetes, muscle strength, and impaired physical function: the tip of the iceberg? Diabetes Care. 2005;28:2541-2.

47. Ryan AS, Buscemi A, Forrester L, Hafer-Macko CE, Ivey FM. Atrophy and intramuscular fat in specific muscles of the thigh: associated weakness and hyperinsulinemia in stroke survivors. Neurorehabil Neural Repair. 2011;25:865-72.

48. Szendroedi J, Phielix E, Roden M. The role of mitochondria in insulin resistance and type 2 diabetes mellitus. Nat Rev Endocrinol. 2012;8:92-103.

49. Brown EC, Buchan DS, Madi SA, Gordon BN, Drignei D. Grip strength cut points for diabetes risk among apparently healthy U.S. adults. Am J Prev Med. 2020;58:757-65.

50. Wu S, Wang R, Zhao Y, Ma X, Wu M, Yan X, et al. The relationship between self-rated health and objective health status: a population-based study. BMC Public Health. 2013;13:320.

51. Fritz NE, McCarthy CJ, Adamo DE. Handgrip strength as a means of monitoring progression of cognitive decline - a scoping review. Ageing Res Rev. 2017;35:112-23.

52. Olivier E, Davare M, Andres M, Fadiga L. Precision grasping in humans: from motor control to cognition. Curr Opin Neurobiol. 2007;17:644-8.

53. Heuninckx S, Wenderoth N, Debaere F, Peeters R, Swinnen SP. Neural basis of aging: the penetration of cognition into action control. J Neurosci. 2005;25:6787-96.

54. Park S, Cho J, Kim D, Jin Y, Lee I, Hong H, et al. Handgrip strength, depression, and all-cause mortality in Korean older adults. BMC Geriatr. 2019;19:127. 
55. Ashdown-Franks G, Stubbs B, Koyanagi A, Schuch F, Firth J, Veronese N, et al. Handgrip strength and depression among 34,129 adults aged 50 years and older in six low- and middle-income countries. J Affect Disord. 2019;243:448-54.

\section{Tables}

Table 1. Sociodemographic characteristics of respondents 


\begin{tabular}{|c|c|c|c|c|c|c|c|c|c|c|c|c|c|c|c|}
\hline \multirow[t]{3}{*}{ Variables } & \multicolumn{5}{|l|}{ Total } & \multicolumn{5}{|l|}{ Male } & \multicolumn{5}{|c|}{ Female } \\
\hline & \multirow[t]{2}{*}{$\mathbf{N}$} & \multirow[t]{2}{*}{ (\%) } & \multicolumn{2}{|c|}{ HGS (kg) } & \multirow[t]{2}{*}{ P-value } & \multirow[t]{2}{*}{$\mathbf{N}$} & \multirow[t]{2}{*}{$(\%)$} & \multicolumn{2}{|c|}{ HGS (kg) } & \multirow[t]{2}{*}{ P-value } & \multirow[t]{2}{*}{$\mathbf{N}$} & \multirow[t]{2}{*}{ (\%) } & \multicolumn{2}{|c|}{ HGS (kg) } & \multirow[t]{2}{*}{ P-value } \\
\hline & & & Mean & SD & & & & Mean & SD & & & & Mean & SD & \\
\hline \multicolumn{16}{|l|}{ Age group $^{1}$} \\
\hline $\begin{array}{l}\text { Young old (60-74 } \\
\text { years) }\end{array}$ & 996 & 82.7 & 26.7 & 8.19 & $<0.001^{\#}$ & 588 & 85.1 & 31.1 & 7.16 & $<0.001^{\star}$ & 408 & 79.5 & 20.5 & 4.82 & $<0.001$ * \\
\hline $\begin{array}{l}\text { Middle old (75-84 } \\
\text { years) }\end{array}$ & 186 & 15.4 & 19.9 & 6.97 & & 96 & 13.9 & 23.8 & 6.49 & & 90 & 17.5 & 15.7 & 4.66 & \\
\hline Old old ( $\geq 85$ years) & 22 & 1.8 & 14.6 & 6.37 & & 7 & 1.0 & 20.9 & 4.57 & & 15 & 2.9 & 11.6 & 4.74 & \\
\hline \multicolumn{16}{|l|}{ Sex } \\
\hline Male & 691 & 57.4 & 30.0 & 7.53 & $<0.001^{\#}$ & & & & & & & & & & \\
\hline Female & 513 & 42.6 & 19.4 & 5.28 & & & & & & & & & & & \\
\hline \multicolumn{16}{|l|}{ Marital status ${ }^{2}$} \\
\hline $\begin{array}{l}\text { Married (living } \\
\text { together) }\end{array}$ & 790 & 65.6 & 28.1 & 8.13 & $<0.001^{\#}$ & 608 & 88.0 & 30.3 & 7.55 & $0.003^{*}$ & 182 & 35.5 & 20.8 & 5.14 & $<0.001^{\#}$ \\
\hline $\begin{array}{l}\text { Married (living } \\
\text { separately) }\end{array}$ & 12 & 1.0 & 27.3 & 8.65 & & 6 & .9 & 33.5 & 8.34 & & 6 & 1.2 & 21.1 & 1.56 & \\
\hline Widowed & 22 & 1.8 & 21.2 & 6.49 & & 4 & .6 & 32.3 & 4.27 & & 18 & 3.5 & 18.8 & 3.71 & \\
\hline Divorced & 362 & 30.1 & 20.0 & 6.31 & & 66 & 9.6 & 26.7 & 6.44 & & 296 & 57.7 & 18.5 & 5.23 & \\
\hline Never married & 18 & 1.5 & 24.0 & 9.22 & & 7 & 1.0 & 29.5 & 9.37 & & 11 & 2.1 & 20.5 & 7.56 & \\
\hline \multicolumn{16}{|l|}{$\begin{array}{l}\text { Household } \\
\text { composition }^{3}\end{array}$} \\
\hline Live alone & 64 & 5.3 & 20.8 & 6.31 & $<0.001^{\#}$ & 13 & 1.9 & 27.9 & 7.12 & $0.566^{*}$ & 51 & 9.9 & 19.0 & 4.64 & $0.777^{\#}$ \\
\hline $\begin{array}{l}\text { Live with blood- } \\
\text { related family }\end{array}$ & 1134 & 94.2 & 25.7 & 8.51 & & 676 & 97.8 & 30.0 & 7.55 & & 458 & 89.3 & 19.4 & 5.30 & \\
\hline $\begin{array}{l}\text { Live with other } \\
\text { family (non-blood- } \\
\text { related) }\end{array}$ & 6 & 0.5 & 24.3 & 10.33 & & 2 & 0.3 & 31.8 & 1.77 & & 4 & 0.8 & 20.5 & 10.98 & \\
\hline \multicolumn{16}{|l|}{ Location } \\
\hline Rural & 602 & 50.0 & 25.3 & 8.63 & $>0.05^{\star}$ & 339 & 49.1 & 29.9 & 7.82 & $0.775^{\star}$ & 263 & 51.3 & 19.3 & 5.29 & $0.668^{*}$ \\
\hline Urban & 602 & 50.0 & 25.7 & 8.34 & & 352 & 50.9 & 30.1 & 7.25 & & 250 & 48.7 & 19.5 & 5.28 & \\
\hline \multicolumn{16}{|l|}{ Education Level ${ }^{4}$} \\
\hline No school & 121 & 10.0 & 19.9 & 6.98 & $<0.001^{\star}$ & 26 & 3.8 & 26.9 & 8.30 & $<0.001^{\star}$ & 95 & 18.5 & 18.0 & 5.18 & $<0.001 *$ \\
\hline Some primary & 202 & 16.8 & 23.4 & 8.33 & & 109 & 15.8 & 28.2 & 7.32 & & 93 & 18.1 & 17.8 & 5.41 & \\
\hline Finished primary & 327 & 27.2 & 24.6 & 8.04 & & 172 & 24.9 & 28.8 & 7.92 & & 155 & 30.2 & 20.0 & 5.02 & \\
\hline Middle school & 328 & 27.2 & 27.1 & 8.32 & & 214 & 31.0 & 30.6 & 7.55 & & 114 & 22.2 & 20.6 & 5.14 & \\
\hline High school & 88 & 7.3 & 29.1 & 7.99 & & 65 & 9.4 & 32.4 & 6.05 & & 23 & 4.5 & 19.8 & 5.01 & \\
\hline Vocational & 10 & 0.8 & 28.9 & 6.33 & & 7 & 1.0 & 31.2 & 5.71 & & 3 & 0.6 & 23.3 & 4.16 & \\
\hline College/university & 113 & 9.4 & 29.9 & 8.02 & & 92 & 13.3 & 32.0 & 7.00 & & 21 & 4.1 & 21.0 & 5.85 & \\
\hline Others & 15 & 1.2 & 22.6 & 6.83 & & 6 & .9 & 28.5 & 4.46 & & 9 & 1.8 & 18.7 & 5.12 & \\
\hline $\begin{array}{l}\text { Current } \\
\text { employment } \\
\text { status }^{5}\end{array}$ & & & & & & & & & & & & & & & \\
\hline Employed & 169 & 14.0 & 29.3 & 7.86 & $<0.001^{\#}$ & 127 & 18.4 & 31.9 & 6.88 & $<0.001 \star$ & 42 & 8.2 & 21.5 & 4.92 & $0.001^{*}$ \\
\hline Retired from job & 868 & 72.1 & 26.1 & 8.31 & & 558 & 80.8 & 29.6 & 7.53 & & 310 & 60.4 & 19.7 & 5.23 & \\
\hline Never had a job & 167 & 13.9 & 18.4 & 5.56 & & 6 & .9 & 21.8 & 11.14 & & 161 & 31.4 & 18.3 & 5.26 & \\
\hline Household income ${ }^{6}$ & & & & & & & & & & & & & & & \\
\hline No income & 50 & 4.2 & 24.4 & 8.03 & $0.003^{*}$ & 28 & 4.1 & 28.4 & 7.79 & $0.101^{*}$ & 22 & 4.3 & 19.4 & 4.99 & $0.759 *$ \\
\hline
\end{tabular}




\begin{tabular}{|c|c|c|c|c|c|c|c|c|c|c|c|c|}
\hline B40 & 1044 & 86.7 & 25.2 & 8.42 & 581 & 84.1 & 29.8 & 7.56 & 463 & 90.3 & 19.4 & 5.25 \\
\hline M40 & 98 & 8.1 & 28.5 & 8.70 & 71 & 10.3 & 31.9 & 6.91 & 27 & 5.3 & 19.6 & 6.25 \\
\hline T20 & 12 & 1.0 & 29.3 & 7.41 & 11 & 1.6 & 29.7 & 7.64 & 1 & 0.2 & 25.0 & . \\
\hline
\end{tabular}

* One-way ANOVA

\# Welch's ANOVA test as homogeneity of variance was violated

1 Post hoc Tamhane's test, all significant

2 Post hoc Tamhane's test, only significance was married and living together with widowed and divorced

3 Post hoc Tamhane's test, the only significance was staying alone and staying with a blood-related family

4 Post hoc Bonferroni, all were significant except 'some primary' with 'finished primary', and middle school, high school and vocational

5 Post hoc Tamhane's test, all were significant

6 Post hoc Bonferroni, the only significance was 'M40' with 'No income' and 'B40'.

Table 2. Bivariate analysis to determine the association between lifestyle factors and handgrip strength (HGS) 


\begin{tabular}{|c|c|c|c|c|c|c|c|c|c|c|c|c|c|c|c|}
\hline \multirow[t]{3}{*}{ Variables } & \multicolumn{5}{|l|}{ Total } & \multicolumn{5}{|c|}{ Male } & \multicolumn{5}{|c|}{ Female } \\
\hline & \multirow[t]{2}{*}{$\mathbf{N}$} & \multirow[t]{2}{*}{$(\%)$} & \multicolumn{2}{|c|}{ HGS (kg) } & \multirow[t]{2}{*}{ P-value } & \multirow[t]{2}{*}{$\mathbf{N}$} & \multirow[t]{2}{*}{$(\%)$} & \multicolumn{2}{|c|}{ HGS (kg) } & \multirow[t]{2}{*}{ P-value } & \multirow[t]{2}{*}{$\mathrm{N}$} & \multirow[t]{2}{*}{$(\%)$} & \multicolumn{2}{|c|}{ HGS (kg) } & \multirow[t]{2}{*}{ P-value } \\
\hline & & & Mean & SD & & & & Mean & SD & & & & Mean & SD & \\
\hline \multicolumn{16}{|l|}{ Smoking status ${ }^{1}$} \\
\hline $\begin{array}{l}\text { Smoke almost } \\
\text { everyday }\end{array}$ & 169 & 14.0 & 31.1 & 7.83 & $<0.001^{\star}$ & 165 & 23.9 & 31.5 & 7.63 & $0.44^{*}$ & 4 & 0.8 & 17.9 & 3.47 & $0.887 *$ \\
\hline Smoke sometimes & 46 & 3.8 & 29.5 & 7.63 & & 41 & 5.9 & 30.7 & 6.91 & & 5 & 1.0 & 19.9 & 6.93 & \\
\hline $\begin{array}{l}\text { Quit less than } 5 \\
\text { years ago }\end{array}$ & 30 & 2.5 & 28.5 & 6.02 & & 29 & 4.2 & 28.6 & 6.06 & & 1 & 0.2 & 24.0 & . & \\
\hline $\begin{array}{l}\text { Quit more than } 5 \\
\text { years ago }\end{array}$ & 179 & 14.9 & 29.0 & 7.59 & & 171 & 24.7 & 29.5 & 7.44 & & 8 & 1.6 & 19.6 & 3.39 & \\
\hline Never smoked & 780 & 64.8 & 23.1 & 7.94 & & 285 & 41.2 & 29.5 & 7.66 & & 495 & 96.5 & 19.4 & 5.31 & \\
\hline \multicolumn{16}{|l|}{$\begin{array}{l}\text { Alcohol } \\
\text { consumption }^{2}\end{array}$} \\
\hline Currently drink & 42 & 3.5 & 30.6 & 8.39 & $<0.001^{\star}$ & 32 & 4.6 & 33.5 & 6.33 & $0.46^{*}$ & 10 & 1.9 & 21.1 & 7.10 & $0.691^{*}$ \\
\hline $\begin{array}{l}\text { Quit less than } 5 \\
\text { years ago }\end{array}$ & 9 & 0.7 & 27.3 & 6.63 & & 8 & 1.2 & 28.0 & 6.70 & & 1 & 0.2 & 21.5 & . & \\
\hline $\begin{array}{l}\text { Quit more than } 5 \\
\text { years ago }\end{array}$ & 69 & 5.7 & 29.1 & 8.24 & & 64 & 9.3 & 30.0 & 7.89 & & 5 & 1.0 & 18.1 & 3.42 & \\
\hline Never drank & 1084 & 90.0 & 25.0 & 8.40 & & 587 & 84.9 & 29.8 & 7.52 & & 497 & 96.9 & 19.4 & 5.26 & \\
\hline \multicolumn{16}{|l|}{ Betel chewing ${ }^{3}$} \\
\hline $\begin{array}{l}\text { Chew almost every } \\
\text { day }\end{array}$ & 18 & 1.5 & 20.2 & 4.26 & $0.003^{\#}$ & 4 & 6 & 21.3 & 4.35 & $0.139 *$ & 14 & 2.7 & 19.9 & 4.35 & $0.178^{*}$ \\
\hline Chew sometimes & 32 & 2.7 & 24.3 & 8.32 & & 18 & 2.6 & 28.6 & 5.85 & & 14 & 2.7 & 18.9 & 7.93 & \\
\hline $\begin{array}{l}\text { Quit chewing less } \\
\text { than } 5 \text { years ago }\end{array}$ & 3 & 0.2 & 23.8 & 3.69 & & 2 & 0.3 & 25.3 & 3.89 & & 1 & .2 & 21.0 & . & \\
\hline $\begin{array}{l}\text { Quit chewing more } \\
\text { than } 5 \text { years ago }\end{array}$ & 90 & 7.5 & 24.2 & 9.34 & & 48 & 6.9 & 30.1 & 7.96 & & 42 & 8.2 & 17.5 & 5.53 & \\
\hline Never chewed & 1061 & 88.1 & 25.7 & 8.44 & & 619 & 89.6 & 30.1 & 7.53 & & 442 & 86.2 & 19.6 & 5.17 & \\
\hline \multicolumn{16}{|l|}{$\begin{array}{l}\text { Strenuous physical } \\
\text { activity }{ }^{4}\end{array}$} \\
\hline $\begin{array}{l}4 \text { or more times a } \\
\text { week }\end{array}$ & 61 & 5.1 & 28.4 & 7.93 & $<0.001^{\star}$ & 45 & 6.5 & 31.4 & 6.42 & $0.001^{\#}$ & 16 & 3.1 & 20.2 & 5.77 & $0.030 *$ \\
\hline 2 or 3 times a week & 56 & 4.7 & 29.4 & 7.49 & & 44 & 6.4 & 32.1 & 5.74 & & 12 & 2.3 & 19.6 & 4.23 & \\
\hline Once a week & 55 & 4.6 & 27.1 & 8.37 & & 32 & 4.6 & 32.1 & 6.08 & & 23 & 4.5 & 20.1 & 5.69 & \\
\hline 1 to 3 times a month & 35 & 2.9 & 31.1 & 8.20 & & 27 & 3.9 & 33.7 & 6.28 & & 8 & 1.6 & 22.4 & 8.14 & \\
\hline A few times a year & 42 & 3.5 & 28.0 & 9.07 & & 25 & 3.6 & 31.5 & 9.91 & & 17 & 3.3 & 22.9 & 4.14 & \\
\hline Rarely/None & 955 & 79.3 & 24.6 & 8.36 & & 518 & 75.0 & 29.3 & 7.65 & & 437 & 85.2 & 19.1 & 5.20 & \\
\hline \multicolumn{16}{|l|}{$\begin{array}{l}\text { Moderate physical } \\
\text { activity }^{5}\end{array}$} \\
\hline $\begin{array}{l}4 \text { or more times a } \\
\text { week }\end{array}$ & 346 & 28.7 & 27.7 & 8.00 & $<0.001^{*}$ & 213 & 30.8 & 32.0 & 6.48 & $<0.001^{\#}$ & 133 & 25.9 & 21.0 & 4.95 & $<0.001^{\star}$ \\
\hline 2 or 3 times a week & 197 & 16.4 & 27.0 & 8.48 & & 120 & 17.4 & 31.6 & 6.71 & & 77 & 15.0 & 19.7 & 5.17 & \\
\hline Once a week & 89 & 7.4 & 26.2 & 7.87 & & 50 & 7.2 & 31.0 & 6.30 & & 39 & 7.6 & 20.0 & 4.68 & \\
\hline 1 to 3 times a month & 70 & 5.8 & 28.1 & 8.50 & & 46 & 6.7 & 31.8 & 7.52 & & 24 & 4.7 & 21.0 & 5.14 & \\
\hline A few times a year & 77 & 6.4 & 26.2 & 8.78 & & 47 & 6.8 & 29.6 & 9.33 & & 30 & 5.8 & 21.6 & 4.86 & \\
\hline Rarely/None & 425 & 35.3 & 22.2 & 7.93 & & 215 & 31.1 & 26.6 & 7.64 & & 210 & 40.9 & 17.7 & 5.23 & \\
\hline \multicolumn{16}{|l|}{$\begin{array}{l}\text { Light physical } \\
\text { activity }^{6}\end{array}$} \\
\hline $\begin{array}{l}4 \text { or more times a } \\
\text { week }\end{array}$ & 679 & 56.4 & 26.1 & 7.95 & $<0.001^{\#}$ & 381 & 55.1 & 30.6 & 6.79 & $0.006^{\#}$ & 298 & 58.1 & 20.2 & 4.96 & $<0.001 *$ \\
\hline
\end{tabular}




\begin{tabular}{|c|c|c|c|c|c|c|c|c|c|c|c|c|}
\hline 2 or 3 times a week & 151 & 12.5 & 26.5 & 8.57 & 96 & 13.9 & 30.5 & 7.45 & 55 & 10.7 & 19.5 & 5.27 \\
\hline Once a week & 67 & 5.6 & 25.9 & 8.95 & 39 & 5.6 & 29.9 & 8.93 & 28 & 5.5 & 20.3 & 5.27 \\
\hline 1 to 3 times a month & 28 & 2.3 & 26.6 & 7.61 & 18 & 2.6 & 29.7 & 7.31 & 10 & 1.9 & 21.0 & 4.28 \\
\hline A few times a year & 25 & 2.1 & 27.0 & 11.82 & 15 & 2.2 & 32.0 & 12.60 & 10 & 1.9 & 19.5 & 4.54 \\
\hline Rarely/None & 254 & 21.1 & 22.9 & 8.94 & 142 & 20.5 & 27.8 & 8.08 & 112 & 21.8 & 16.7 & 5.47 \\
\hline
\end{tabular}

* One-way ANOVA \# Welch's ANOVA test as homogeneity of variance was violated

$1=$ Post hoc Bonferroni, the only significance was 'never smoking' with others

2 = Post hoc Bonferroni, the significance was 'currently drink' with 'never drank', and 'quit more than 5 years ago with 'never drank.'

$3=$ Post hoc Tamhane's test, the only significance was 'chew almost every day' with 'never chewed.'

4 = Post hoc Bonferroni, the only significance was 'rarely/none' with ' 4 or more times a week', '2 or 3 times a week' and ' 1 to 3 times a month'.

$5=$ Post hoc Bonferroni test, the only significance was 'rarely/none' with all other exercise frequencies

6 = Post hoc Tamhane's test, the only significance was 'rarely/none' with ' 4 or more times a week' and ' 2 or 3 times a week'.

Table 3. Bivariate analysis to determine the association between comorbidity and handgrip strength (HGS) 


\begin{tabular}{|c|c|c|c|c|c|c|c|c|c|c|c|c|c|c|c|}
\hline \multirow[t]{3}{*}{ Variables } & \multicolumn{5}{|l|}{ Total } & \multicolumn{5}{|c|}{ Male } & \multicolumn{5}{|c|}{ Female } \\
\hline & \multirow[t]{2}{*}{$\mathbf{N}$} & \multirow[t]{2}{*}{$(\%)$} & \multicolumn{2}{|c|}{ HGS (kg) } & \multirow[t]{2}{*}{ P-value } & \multirow[t]{2}{*}{$\mathbf{N}$} & \multirow[t]{2}{*}{ (\%) } & \multicolumn{2}{|c|}{ HGS (kg) } & \multirow[t]{2}{*}{ P-value } & \multirow[t]{2}{*}{$\mathbf{N}$} & \multirow[t]{2}{*}{$(\%)$} & \multicolumn{2}{|c|}{ HGS (kg) } & \multirow{2}{*}{$\begin{array}{l}\mathrm{P}- \\
\text { valu }\end{array}$} \\
\hline & & & Mean & SD & & & & Mean & SD & & & & Mean & SD & \\
\hline \multicolumn{16}{|l|}{ BMI class $^{1}$} \\
\hline Underweight & 39 & 3.2 & 20.7 & 7.76 & 0.003 & 22 & 3.2 & 24.5 & 7.69 & $<0.001$ & 17 & 3.3 & 15.7 & 4.40 & $<0.0$ \\
\hline Normal & 223 & 18.5 & 25.1 & 8.26 & & 148 & 21.4 & 28.7 & 7.04 & & 75 & 14.6 & 18.1 & 5.52 & \\
\hline Pre-Obese & 454 & 37.7 & 26.2 & 8.39 & & 271 & 39.2 & 31.0 & 6.69 & & 183 & 35.7 & 19.0 & 4.58 & \\
\hline Obese I & 410 & 34.1 & 25.4 & 8.75 & & 216 & 31.3 & 30.1 & 8.37 & & 194 & 37.8 & 20.3 & 5.73 & \\
\hline Obese II & 61 & 5.1 & 24.7 & 8.41 & & 27 & 3.9 & 29.9 & 9.13 & & 34 & 6.6 & 20.5 & 4.81 & \\
\hline Obese III & 17 & 1.4 & 26.1 & 5.71 & & 7 & 1.0 & 31.6 & 2.71 & & 10 & 1.9 & 22.4 & 3.77 & \\
\hline \multicolumn{16}{|l|}{ Hypertension } \\
\hline Yes & 775 & 64.4 & 24.8 & 8.49 & $<0.001^{\#}$ & 420 & 60.8 & 29.7 & 7.55 & $0.164^{\star}$ & 355 & 69.2 & 19.0 & 5.26 & 0.00 \\
\hline No & 429 & 35.6 & 26.7 & 8.33 & & 271 & 39.2 & 30.5 & 7.47 & & 158 & 30.8 & 20.3 & 5.24 & \\
\hline \multicolumn{16}{|l|}{ Stroke } \\
\hline Yes & 48 & 4.0 & 24.3 & 8.45 & $0.323^{\#}$ & 29 & 4.2 & 28.9 & 8.12 & $0.425^{\star}$ & 19 & 3.7 & 17.2 & 5.82 & 0.07 \\
\hline No & 1156 & 96.0 & 25.5 & 9.25 & & 662 & 95.8 & 30.0 & 7.50 & & 494 & 96.3 & 19.5 & 5.25 & \\
\hline \multicolumn{16}{|l|}{ Heart Disease } \\
\hline Yes & 139 & 11.5 & 25.4 & 8.31 & $0.936^{\#}$ & 99 & 14.3 & 28.8 & 6.90 & $0.099 *$ & 40 & 7.8 & 17.0 & 4.65 & 0.00 \\
\hline No & 1065 & 88.5 & 25.5 & 8.51 & & 592 & 85.7 & 30.2 & 7.62 & & 473 & 92.2 & 19.6 & 5.29 & \\
\hline \multicolumn{16}{|l|}{ Diabetes Mellitus } \\
\hline Yes & 434 & 36.0 & 24.3 & 8.15 & $<0.001^{\#}$ & 242 & 35.0 & 28.5 & 7.79 & $<0.001^{\star}$ & 192 & 37.4 & 19.0 & 4.93 & 0.23 \\
\hline No & 770 & 64.0 & 26.1 & 8.59 & & 449 & 65.0 & 30.8 & 7.26 & & 321 & 62.6 & 19.6 & 5.48 & \\
\hline Dyslipidaemia & & & & & & & & & & & & & & & \\
\hline Yes & 570 & 47.3 & 25.1 & 8.08 & $0.139^{\#}$ & 316 & 45.7 & 29.5 & 7.24 & $0.128^{*}$ & 254 & 49.5 & 19.6 & 5.17 & 0.39 \\
\hline No & 634 & 52.7 & 25.8 & 8.82 & & 375 & 54.3 & 30.4 & 7.75 & & 259 & 50.5 & 19.2 & 5.40 & \\
\hline Cancer & & & & & & & & & & & & & & & \\
\hline Yes & 25 & 2.1 & 21.1 & 6.89 & $<0.009 *$ & 11 & 1.6 & 24.7 & 8.07 & $0.019 *$ & 14 & 2.7 & 18.2 & 4.17 & 0.40 \\
\hline No & 1179 & 97.9 & 25.6 & 8.49 & & 680 & 98.4 & 30.1 & 7.50 & & 499 & 97.3 & 19.4 & 5.31 & \\
\hline Depression & & & & & & & & & & & & & & & \\
\hline Yes & 4 & 0.3 & 22.4 & 8.60 & $0.956^{\#}$ & 2 & 0.3 & 27.3 & 8.13 & $0.607^{*}$ & 2 & 0.4 & 17.5 & 7.78 & 0.61 \\
\hline No & 1200 & 99.7 & 25.5 & 8.49 & & 689 & 99.7 & 30.0 & 7.53 & & 511 & 99.6 & 19.4 & 5.28 & \\
\hline $\begin{array}{l}\text { Difficulty of } \\
\text { remembering/concen }\end{array}$ & & & & & & & & & & & & & & & \\
\hline No difficulty & 744 & 61.8 & 26.3 & 8.44 & $<0.001^{\star}$ & 437 & 63.2 & 30.7 & 7.42 & $0.001^{*}$ & 307 & 59.8 & 20.0 & 5.18 & 0.00 \\
\hline Yes, some difficulty & 440 & 36.5 & 24.2 & 8.37 & & 243 & 35.2 & 29.0 & 7.41 & & 197 & 38.4 & 18.4 & 5.24 & \\
\hline Yes, a lot of difficulty & 18 & 1.2 & 20.7 & 8.57 & & 9 & 1.3 & 23.1 & 9.72 & & 9 & 1.8 & 18.4 & 7.01 & \\
\hline Cannot do at all & 2 & 0.2 & 24.8 & 8.13 & & 2 & 0.3 & 24.8 & 8.13 & & - & - & - & - & \\
\hline Self-rated health stat & & & & & & & & & & & & & & & \\
\hline Excellent & 44 & 3.7 & 28.2 & 8.70 & $<0.001^{\star}$ & 27 & 3.9 & 32.7 & 7.62 & $<0.001^{\star}$ & 17 & 3.3 & 21.0 & 4.41 & 0.16 \\
\hline Good & 668 & 55.5 & 25.9 & 8.39 & & 376 & 54.4 & 30.9 & 6.95 & & 292 & 56.9 & 19.5 & 5.16 & \\
\hline Fair & 441 & 36.6 & 25.1 & 8.54 & & 264 & 38.2 & 29.0 & 8.05 & & 177 & 34.5 & 19.2 & 5.25 & \\
\hline Poor & 51 & 4.2 & 20.5 & 7.08 & & 24 & 3.5 & 23.7 & 5.85 & & 27 & 5.3 & 17.6 & 6.93 & \\
\hline
\end{tabular}


* One-way ANOVA \# Independent T-Test

1 = Post hoc Bonferroni, the only significance was underweight with normal, preobese, obese I, and obese II

2 = Post hoc Bonferroni, the only significance was 'normal' with 'mild' and 'normal' with 'moderate'.

$3=$ Post hoc Bonferroni, the only significance was poor with excellent, good and fair

Table 4. Comparison of HGS between sexes while controlling for potential cofounders

\begin{tabular}{|c|c|c|c|c|c|}
\hline & $\mathbf{N}$ & Adj mean $(95 \% \mathrm{Cl})^{\mathrm{a}}$ & \multicolumn{2}{|c|}{ Adj mean diff $(95 \% \mathrm{Cl})^{b}$} & $P$ value \\
\hline \multicolumn{6}{|l|}{ Male } \\
\hline \multirow[t]{2}{*}{ Young old } & 588 & $24.7(19.60,29.82)$ & Middle old & $5.4(3.51,7.28)$ & $<0.001$ \\
\hline & & & Old old & $3.4(-3.06,9.89)$ & 0.618 \\
\hline \multirow[t]{2}{*}{ Middle old } & 96 & $19.3(14.16,24.46)$ & Young old & $-5.4(-7.28,-3.51)$ & $<0.001$ \\
\hline & & & Old old & $-2.0(-8.47,4.51)$ & 1.000 \\
\hline \multirow[t]{2}{*}{ Old old } & 7 & $21.3(14.50,28.09)$ & Young old & $-3.4(-9.89,3.06)$ & 0.618 \\
\hline & & & Middle old & $2.0(-4.51,8.47)$ & 1.000 \\
\hline \multicolumn{6}{|l|}{ Female } \\
\hline \multirow[t]{2}{*}{ Young old } & 408 & $20.4(17.98,22.75)$ & Middle old & $2.9(1.42,4.33)$ & $<0.001$ \\
\hline & & & Old old & $6.3(3.25,9.42)$ & $<0.001$ \\
\hline \multirow[t]{2}{*}{ Middle old } & 90 & $17.5(14.86,20.13)$ & Young old & $-2.9(-4.33,-1.42)$ & $<0.001$ \\
\hline & & & Old old & $3.5(0.33,6.58)$ & 0.025 \\
\hline \multirow[t]{2}{*}{ Old old } & 15 & $14.0(10.67,17.40)$ & Young old & $-6.3(-9.42,-3.25)$ & $<0.001$ \\
\hline & & & Middle old & $-3.5(-6.58,-0.33)$ & 0.025 \\
\hline
\end{tabular}

a Adjusted mean using ANCOVA

${ }^{b}$ Bonferroni adjustment for $95 \%$ confidence interval for difference 